\title{
El carácter compilatorio del ms. 126 del Archivo Capitular de El Burgo de Osma ${ }^{1}$
}

\author{
Nuria Del CAStillo Lebourgeois \\ Universidad Complutense de Madrid \\ nuriadelcastillo@ucm.es
}

Recibido: 23 de diciembre de 2014

Aceptado: 12 de marzo de 2015

\section{RESUMEN}

En este trabajo se aborda el estudio de aquellos aspectos que nos llevan a considerar al ms. 126 del Archivo Capitular de El Burgo de Osma un códice compilatorio: por una parte, la identificación de las fuentes de las que beben dos de sus glosas de contenido mitológico y, por otra, el análisis de la estructura del códice en su conjunto y de la relación entre las obras que lo componen.

Palabras clave: Manuscrito 126 de El Burgo de Osma. Historia hierosolymitana. De excidio Troiae historia. Excidium Troiae. Historia Karoli Magni. Balderico. Dares. Turpino.

Del Castillo Lebourgeois, N., «El carácter compilatorio del ms. 126 del Archivo Capitular de El Burgo de Osma», Cuad. Fil. Clás. Estud. Lat. 35.1 (2015) 101-118.

The compilatory nature of the 126 manuscript

of Archivo Capitular de El Burgo de Osma

\begin{abstract}
In this paper I study those aspect that lead us to consider the ms. 126 of Archivo Capitular de El Burgo de Osma a compilatory codex: on the one hand, I will identify the sources of two glosses with mythological nature and, on the other, I will analize the structure of the whole codex and the link between its literary works.
\end{abstract}

Keywords: 126 manuscript El Burgo de Osma. Historia Hierosolymitana. De excidio Troiae historia. Excidium Troiae. Historia Karoli Magni. Baldric. Dares. Turpin.

SuMARIO: 1. Introducción. 2. Análisis de las glosas. 2.1. Primera glosa: el sueño de Hécuba y la juventud de Paris. 2.2. Segunda glosa: invulnerabilidad y muerte de Aquiles. 3. Disposición y contextualización del Excidium Troiae. 4. Conclusiones. 5. Referencias bibliográficas. 6. Anexo.

\footnotetext{
${ }^{1}$ Este trabajo se inserta en el marco del Proyecto de Investigación «Poetas romanos en la literatura española» (FFI2008-05658/FILO). La procedencia de las imágenes (Fig.1 y 2) es la siguiente: ARCHIVO CAPITULAR DE BURGO DE OSMA, AC, ms. 126. SRDAE C. 787.
} 


\section{INTRODUCCIÓN}

El ms. 126 del Archivo Capitular de El Burgo de Osma es un códice en pergamino del siglo XIII, escrito a dos columnas y que presenta un contenido que, en el momento de su copia, se tenía por historiográfico²: la Historia Hierosolymitana de Balderico (ff.1r-61ra) ${ }^{3}$, la De excidio Troiae historia de Dares ${ }^{4}$ (ff.61rb-72va), el recientemente descubierto Excidium Troiae ${ }^{5}$ (ff.72vb-82v) y la Historia Karoli Magni de Pseudo Turpino (ff.83r-118r).

El Excidium Troiae ${ }^{6}$ ofrece un contenido estructurado de forma tripartita: en primer lugar, refiere los orígenes de Troya y su destrucción (caps.1-147) -basándose en fuentes mitográficas griegas y la Aquileida de Estacio-, la segunda parte habla sobre los viajes de Eneas (caps.15-70) -haciendo una suerte de resumen de la Eneida- y, por último, un breve informe sobre la sucesión de Eneas, los reyes de Alba y la fundación de Roma (caps.71-76) -cercano a Plutarco y Dionisio de Halicarnaso-. No obstante, el Excidium Troiae del códice que nos ocupa presenta una particularidad, y es que reproduce únicamente la segunda y tercera parte del texto, comenzando directamente en el capítulo 28 con los viajes de Eneas ${ }^{8}$. Por tanto, queda excluido todo lo que concierne a Troya, sus orígenes, el conflicto y su subsiguiente destrucción, algo de lo que ya se da cuenta en la obra precedente, la De excidio Troiae historia ${ }^{9}$. Esta

2 Para descripciones del códice $c f$. Rojo Orcajo (1929, p.213), Grubbs (1933, p.90), Rubio Fernández (1984, p.44), Faivre d'Arcier (2006, p.102) y Biddlecombe (2014, p.xcvii). En estas descripciones no se incluye el Excidium Troiae por desconocimiento de su existencia.

${ }^{3}$ En realidad, la Historia Hierosolymitana abarca los ff.1r-59r, puesto que entre el 59v y el 61ra. lo que encontramos es el Exordium Cisterii y la Summa Cartae Caritatis, aunque su existencia tampoco aparece reflejada en las descripciones anteriormente mencionadas. $C f$. Tischler (2002).

${ }^{4}$ Actualmente para esta obra se continúa considerando que la edición de referencia es la de Meister (1873), puesto que las otras dos ediciones existentes se basan sólo en un testimonio: Dederich (1835) utiliza el ms. G y Stolhmann (1968), la última, emplea el ms. Paris 8430; para conocer el panorama de la tradición manuscrita $c f$. Pavano (1993, pp.525-532) y el más reciente y completo Faivre D’Arcier (2006); para una traducción al castellano $c f$. Cristóbal-Del Barrio (2001).

${ }^{5}$ Cf. Del Castillo (2014, pp.61-72). En este artículo se da cuenta del hallazgo de este testimonio, desconocido hasta el momento, se lleva a cabo una breve valoración de su texto y una descripción codicológica del manuscrito algo más extensa que las precedentes.

${ }^{6}$ Se trata de una obra anónima para la que los editores proponen una doble datación -un estadio original llevado a cabo entre los siglos IV y VI d. C. y una reescritura de época protomedieval (Atwood - Withaker 1944)- y que tuvo una importante difusión durante el Medievo.

${ }^{7}$ La división por capítulos la encontramos únicamente en la segunda y más reciente edición: Bate (1986).

${ }^{8}$ Esto mismo ocurre en el único testimonio manuscrito del Excidium Troiae que se conocía en nuestro país hasta el momento: el Matritensis 10046, antes Toletanus 47-4, escrito en el siglo XIV en España. Para su descripción $c f$. Octavio de Toledo (1903, p.89); Pellegrin (1953, p.13) y Rubio Fernández (1984, pp.360-361). Los ms. 126 y 10046 presentan similitudes textuales, codicológicas y de contenido; además de reproducir el mencionado esquema De excidio Troiae historia $+2^{\mathrm{a}}$ y $3^{\mathrm{a}}$ parte del Excidium Troiae ofrecen la misma 'reelaboración' de esta última. Podríamos llegar a considerar, gracias a errores separativos y correcciones, que el uno es copia directa del otro. $C f$. Del Castillo (2014).

${ }^{9}$ La obra, estructurada en 54 capítulos de acuerdo con la edición de Meister (1874), comienza narrando acontecimientos anteriores al rapto de Helena -expedición argonáutica que hace escala en Troya y toma como prisionera a Hesíone- y termina con la conquista de la ciudad sin informar, como sí se hacía en la 
circunstancia podría deberse a algo tan sencillo como que el copista del ms. 126 hubiera copiado esta combinación tal cual de su modelo, pues son muchos los códices que reproducen ambas obras, aunque no con este mismo esquema ${ }^{10}$. No obstante, el propósito de este trabajo es intentar demostrar que la falta de la mencionada primera parte del Excidium Troiae supone un acto consciente y voluntario por parte del copista y que, además, responde a un motivo concreto.

A lo largo de las siguientes páginas tendremos en cuenta las glosas de contenido mitológico que presenta el códice y la disposición y relación del Excidium Troiae respecto a las otras obras que lo componen para tratar de probar lo que ahora es una mera hipótesis.

\section{ANÁLISIS DE LAS GLOSAS}

El presente códice ofrece dos tipos fundamentales de adiciones o glosas: aquellas que completan el texto principal, es decir, que añaden una porción que, por descuido o por falta de espacio, no se hubiera reproducido ${ }^{11}$, y aquellas en las que el amanuense comenta un determinado contenido ${ }^{12}$. Estas últimas tan sólo aparecen en las dos obras centrales -la De excidio Troaie historia y el Excidium Troiae- y en ellas se desarrollan reflexiones de carácter moral traídas a colación a propósito de algún pasaje concreto de la obra a la que glosan ${ }^{13}$. No obstante, el códice presenta dos glosas que escapan a esta estructura, pues el episodio mitológico que actúa como punto de partida del comentario no está tomado de la obra glosada, la De excidio Troiae historia de Dares, sino que bebe de otra fuente. A continuación, intentaremos identificar cuál es esa otra fuente.

Ephemerys belli troiani de Dictis, sobre el regreso de los griegos a su patria, puesto que el relato de Dares está configurado desde una perspectiva filotroyana.

${ }^{10}$ Nos estamos refiriendo a los siguientes manuscritos -todos ellos anteriores al que aquí nos ocupa-: Paris, Bibliothèque Nationale de France, lat. 5692, s.XIV; Charleville-Mézières, Bibl. Municipale 275, s.XIII-XIV; Paris, Bibliothèque Nationale de France, N. Acq. lat. 1423, finales del s.XIII; Città del Vaticano, Bibl. Apostolica Vaticana, Reg. lat. 657, ss.XIII-XIV; Bruxelles, Bibl. Royal 3897-3919, seg. mitad del s.XII; Firenze, Bibl. Riccardiana 881, s.XIV y Firenze, Bibl. Medicea-Laurenziana, Plut. LXVI, 40, s.IX.

${ }^{11}$ Estas adiciones las encontramos únicamente en la primera y última obra y pueden ser interlineales -en caso de que el añadido sea breve- o marginales -si la porción a añadir es algo más extensa-. $C f$. Del Castillo (2014).

${ }^{12}$ La única referencia que encontramos a este tipo de glosas está en Rojo Orcajo (1929, p.213): «En este tratado hay varias anotaciones y aplicaciones a la vida espiritual». No se hace mención alguna de los episodios mitológicos incluidos en algunas de ellas.

${ }^{13}$ Uno de los mejores ejemplos para ilustrarlo es la glosa que aparece en el f.68v, en la que se comenta el pasaje del capítulo XX de la De excidio Troiae historia en el que Palamedes está arengando al pueblo para provocar una sedición. Esta glosa termina con la sentencia: Noverat namque sui animi dominatorem urbium subiugatore esse meliorem («Es bien sabido que es mejor el que domina su ánimo que el que subyuga ciudades»). 


\subsection{PRIMERA GLOSA: EL SUEÑO DE HÉCUBA Y LA JUVENTUD DE PARIS}

La primera glosa que vamos a tener en consideración se ubica en el margen izquierdo del f. 62v., casi al comienzo de la De excidio Troiae historia (Fig. 1). Su transcripción es la siguiente ${ }^{14}$ :

Hic ut dicit Homerus binomius fuit. Dictus est enim Alexander et Paris a quo dicta est civitas Parisius. Hic idem fuit pastor in montibus vacarum taurorum id est superborum non ovium et agnorum id est humilium. Cum enim adhuc gestaretur utero Heccube vidit mater eius flammam se peperisse. cuius flamme ardoribus incendebatur tota Troya radicitus. Cum igitur natus fuisset parvulus illa territa his visionibus fecit eum eicere extra in montibus. Quem quidam pastor enutrivit et adultum in Dideo ${ }^{15}$ monte qui sub Troya est secum pastorem fecit.

En esta glosa se refiere el sueño premonitorio de Hécuba durante su preñez de Paris, la consecuente exposición del mismo en el monte Ida, su crianza y su juventud como pastor. Nada se nos dice sobre esto en Dares, quien, al presentarse como militante del bando troyano en la mismísima Guerra de Troya y, por tanto, testigo ocular de aquellos hechos que narra, pretende rehuir cualquier relato que presente tintes fantasiosos ${ }^{16}$. Esta referencia también está ausente en el 'Homero' al que aparece atribuida ${ }^{17}$.

Son muchas las fuentes, tanto griegas como latinas, que dan cuenta de estos episodios y de las que su autor pudo informarse ${ }^{18}$, aunque consideramos que la glosa en cuestión está más cercana, por la similitud de su contenido y por las coincidencias léxicas, a la versión de los hechos que ofrece el Excidium Troiae en su primera parte, concretamente en el cap. $3^{19}$ :

Hecuba regina natus; quem dum regina adhuc pregnans in utero haberet, per somnium vidit se peperisse flammam. que flamma totam troiam circuit et eam incendit.

${ }^{14}$ En los dos casos a analizar, sólo transcribiremos el texto correspondiente a la parte mitológica.

${ }^{15}$ Corrupción del nombre propio 'Ideo', es decir, el monte Ida, lugar donde fue abandonado Paris y donde se produjo el célebre juicio.

${ }^{16}$ A pesar de que la Ephemeris belli troiani de Dictis bebe de la misma tradición antihomérica e historicista que Dares, da cabida al sueño de Hécuba y ofrece del mismo un relato bastante más detallado que el que observamos en muchas de las fuentes que lo mencionan.

${ }^{17}$ Tanto en este caso como en el de la otra glosa, no debemos pensar en el autor de la Ilíada, pues al decir Homerus se está haciendo referencia a la Ilias Latina-también conocida como Liber Homeri u Omerulus, por su brevedad-. Desde el final de la Antigüedad y durante toda la Edad Media esta versión latina de la Ilíada fue la única vía por la que se conservó el recuerdo del poema homérico en la cultura europea occidental. $C f$. Cristóbal-Del Barrio (2001).

${ }^{18}$ Encontramos referencias al sueño de Hécuba en Pr. (paean 8.29-33: texto inseguro); E. Andr.293300 y Tr.919-922; Schol. Lyc.225 y 913; Verg.Aen.7.319-320; 10.704s.; Ov.Epist.16.45-49; 17.237-240; Apollod.3.12.5; Hyg.Fab.91; Cic.Div.1.21.42; schol. Il. 3.325; 12.93; schol.Andr.293; SERV. Aen.7.320 y 10.705; Мүтн.Vат.2.197 у Dict.3.26.

${ }^{19}$ Para las transcripciones de los textos vamos a tener en cuenta la edición de Bate, pues para su elaboración se utilizaron un mayor número de testimonios manuscritos. 
que dum templa consuleret, quenam visio talis esset, responsum est ei quia si quid de ea nasceretur, per ipsum Troia periret. quod et contigit. hoc metuens, dum eum peperisset pro augurio, ut per ipsum omne augurium a Troia tolleretur, ancillis precipit ut eum extra urbem in montibus proicerent. quod et factum est. et dum ab ancillis proiectus fuisset, a quodam pastore qui in eodem monte fuit collectus est et ab eo nutritus est. qui dum adulesceret, coepit eum nutritor suus in vestibus magnis, tamen in habitu pastorali ducere.

Como se puede ver, en ambos casos se hace notar la idea de que Hécuba, durante su embarazo, sueña que va a parir una 'llama', interpretándose que esa misma será la que, en un futuro, incendie Troya desde sus cimientos, aunque bien es cierto que, debido al afán sintetizador de la glosa, en ésta se expone directamente la interpretación del sueño sin dar cuenta de cómo se ha llegado a ella o a quién se ha consultado para su desciframiento ${ }^{20}$. A tenor de esto, resulta interesante reparar en que ambos textos coinciden en la utilización de la palabra flamma a la hora de referirse al objeto de la profecía. Atwood y Withaker -los artífices de la primera edición del Excidium Troiae - al dar cuenta del episodio en su introducción, entienden flamma como 'firebrand' (Atwood y Whitaker 1944, p.43), es decir, 'tea', 'antorcha' o ‘tizón', lo que consideramos una licencia del todo admisible teniendo en cuenta el predominio de este elemento en la tradición; no obstante resulta preciso notar que en las fuentes latinas la palabra que siempre se utiliza en este contexto es fax y no flamma, aunque en ocasiones puede ir acompañada de algún adjetivo relacionado con el fuego ${ }^{21}$. Nos parece, por tanto, que debemos tener en cuenta esta interesante coincidencia léxica que, desde luego, no será la única.

A continuación, podemos observar que tanto en el Excidium Troiae como en el texto glosado las consecuencias que este funesto augurio tiene sobre el destino de Paris son las mismas: su madre -sin intervención alguna por parte de Príamo-, aterrorizada por la visión, ordena que se abandone al recién nacido en los montes que quedan fuera de la ciudad, misión que encomienda a sus sirvientas ${ }^{22}$. Las dos únicas fuentes -a excepción, por supuesto, del Excidium Troiae- en las que el soberano de Troya desconoce el estremecedor sueño de su esposa son Higino y Dictis. Sin em-

\footnotetext{
${ }^{20}$ Existen diversas versiones sobre quién interpretó el sueño de la soberana. En E.Andr.296-300 es Casandra, la propia hermana de Paris, la que aconseja que se mate al niño; que el vaticinio del sueño fue emitido por Ésaco - hijastro de Hécuba que había heredado el don de la profecía de su abuelo materno Mérope- lo encontramos en APOLLOD.3.12.5 y en SCHOL. Lyc.224; por Ésaco, pero sólo predicción de que cierto día nacería un niño que podría causar la destrucción de Troya, en SERV.Aen.2.32; por adivinos de Apolo, o por adivinos y expertos en sueños, sin nombrarlos, en PI. paean 8.43s. (texto inseguro), Ov.Epist.17.239s. y 16.48s., Hyg.Fab.91, schol.Il.3.325, Dict.3.26 (en cuyo caso, la visión de Hécuba tenía tantos detalles que casi no les quedaba nada que interpretar a los adivinos) y, como hemos visto, en Excidium Troiae 3.

${ }^{21}$ La utilización únicamente de la palabra fax la encontramos en VERG.Aen.7.319-320 y 10.704 s.; SERV. Aen.7.320 y 10.705; el empleo de fax acompañada de un adjetivo normalmente vinculado con el fuego está atestiguado en Ov.Epist.16.46 flammiferam facem; Ov.Epist.17.239 fax [...] cruentam; HyG.Fab.91 facem ardentem; Cic.Div.1.42 ardentem facem y DicT.3.26 gravidam facem [...] cuius ignibus.

${ }^{22}$ Mientras que en el Excidium Troiae se alude a las ancillae como destinatarias del encargo, en la glosa no se llega a especificar, aunque la noción queda implícita en la expresión fecit eum eicere.
} 
bargo el devenir de los acontecimientos evoluciona de forma diferente: los adivinos, entendiendo el significado de aquella visión, resuelven asesinar al niño en cuanto nazca, pero finalmente es salvado gracias a la misericordia de los sirvientes -Higinoo de la propia Hécuba, que lo entrega a escondidas a unos pastores para que lo críen en el monte Ida -Dictis-.

Posteriormente, en la glosa se aduce el dato de que Paris fue recogido por un pastor desconocido ${ }^{23}$, algo en lo que vuelve a coincidir con el Excidium Troiae, y que de él aprendió el oficio. Sin embargo, al comienzo nos da una referencia mucho más concreta: el rebaño del joven pastor es un tanto inusual, pues no está compuesto por corderos y ovejas, sino por toros y vacas. La identificación de Paris como pastor de toros aparece muy poco en las fuentes clásicas, la encontramos tan solo en Higino Fab. 91 y en el Excidium Troiae 3, aunque sus relatos difieren notablemente entre sí.

En Higino la alusión al toro constituye el núcleo del relato del reconocimiento de Paris: con motivo del aniversario de su exposición, Príamo ordena que se organicen unos espléndidos juegos fúnebres, para los cuales encargaron que fuera traído el mejor toro de los rebaños del Ida, destinado a ser el premio del vencedor. El encargado de traer el toro escoge uno especialmente apreciado por Paris, quien acude a Troya para tomar parte en los juegos, con la esperanza de recuperarle; y así sucede, pues vence en todas las pruebas y a todos los concursantes, incluidos sus hermanos, por lo que éstos deciden matarlo, abochornados por su derrota. No obstante, Casandra se convierte en la propiciadora activa de la anagnórisis: poseída por un delirio proféti$\mathrm{co}$, anuncia que aquel chico es el niño que en otro tiempo fue expuesto y, su familia, creyendo excepcionalmente en sus palabras, lo reconoce ${ }^{24}$.

El Excidium Troiae ofrece una versión similar del reconocimiento de Paris ${ }^{25}$, aunque la mención al toro no forma parte de ella, sino que constituye el germen de un episodio marginal acaecido durante su juventud en el monte Ida, pero que resultará de vital importancia para los acontecimientos futuros (cap.3): a Paris, que se estaba convirtiendo en un joven de gran inteligencia, le nació en su rebaño un toro de un tamaño asombroso que pronto se convertiría en su predilecto; éste luchaba con los astados de otros pastores y en todos los combates salía victorioso, por lo que el muchacho siempre le colocaba una corona de oro entre los cuernos. Al ser el dios Marte testigo de ello, resolvió tomar la forma de toro y medirse con el magnífico ejemplar de Paris;

\footnotetext{
${ }^{23}$ Las versiones sobre quién encuentra y cuida de Paris son numerosas y variopintas en la tradición grecolatina, por poner algunos ejemplos en APOLLOD.3.12.5 es recogido por Agelao -el mismo encargado de abandonarle-, llevado a su casa y criado como suyo; en HYG.Fab.91 el recién nacido es amparado por unos pastores, no nombrados, que le acogen y le cuidan; en el Мүтн. VAт.2.197 y en Dict.3.26 Hécuba entrega al niño a un pastor de confianza -o pastores, en el caso de Dictis- para su crianza.

${ }^{24}$ Este relato, a excepción del detalle del toro, vuelve a recogerse en Hyg.Fab.273 y también está atestiguado en Ov.Epist.16.359s. y SERV.Aen.5.370.

${ }^{25}$ En Excidium Troiae 5 Paris decide participar en unos espectáculos que solían celebrarse en Troya, ciudad donde reina su padre, a pesar de que el pastor a su cargo intenta disuadirle de su empeño. Allí, a causa de la exhibición de destreza ofrecida en las distintas competiciones, se gana la enemistad de muchos, entre ellos, de sus hermanos. Éstos planean matarle, sin embargo el pastor interviene a tiempo y desvela tanto a Príamo como a sus hijos la verdadera identidad del joven.
} 
en esta ocasión, como no podía ser de otra manera, el dios de la guerra triunfó, por lo que el joven hubo de colocarle a Marte la corona con la que solía agasajar a su toro. Por esta razón, a partir de ese momento Paris será considerado un iudex iustus y Júpiter delegará en él la tarea de elegir a la diosa más bella en la célebre disputa por la manzana de oro ${ }^{26}$ :

Et iam inter alios pastores coepit opinatissimus esse. Cui Paridi in armento suo taurus mire magnitudinis natus est. Qui taurus cum tauris aliorum pastorum dimicabat et singulos vincebat. Quem dum Paris semper victorem videret, ei coronam auream inter cornua inponebat. Hoc videns, Mars in similitudinem tauri aptavit et cum tauro Paridis se ad dimicandum ostendit. Qui dum Mars in similitudinem tauri cum tauro Paridis dimicaret, Mars victor extitit. Tunc Paris, videns Martem in similitudinem tauri taurum superasse, coronam quam tauro suo inponebat Marti inposuit. Et propter quod iustitiam secutus est et sibi non cohibuit, iudex iustus appellatus est.

Desgraciadamente la glosa sólo hace una escueta y somera mención acerca de este tema y no ofrece detalles que nos permitan adscribirlo a una fuente $u$ otra sin temor a equivocarnos.

De cualquier manera, creemos que en casos como éste en el que el contenido nos resulta un tanto ambiguo, atender a la dimensión formal de los textos puede arrojar mucha luz. Por ello no podemos pasar por alto la existencia de un elevado número de concomitancias léxicas que nuestra glosa mantiene con el Excidium Troiae. En algunas ocasiones se aprecia un intento por parte del copista de introducir ciertas variaciones, pero en otras, las expresiones e incluso la sintaxis empleada constituyen una clara reproducción del texto del Excidium.

\begin{tabular}{|c|c|}
\hline Glosa & Excidium Troiae \\
\hline $\begin{array}{l}\text { Cum enim adhuc gestaretur utero } \\
\text { Heccube vidit mater eius flammam } \\
\text { se peperisse. cuius flamme ardoribus } \\
\underline{\text { incendebatur tota Troya radicitus. }}\end{array}$ & $\begin{array}{l}\text { Hecuba regina natus; quem dum regina adhuc } \\
\text { pregnans in utero haberet, per somnium vidit se } \\
\text { peperisse flammam. que flamma totam troiam } \\
\text { circuit et eam incendit. }\end{array}$ \\
\hline $\begin{array}{l}\text { Cum igitur natus fuisset parvulus } \\
\text { illa cerrita his visionibus fecit eum } \\
\text { eicere extra in montibus. }\end{array}$ & $\begin{array}{l}\text { hoc metuens, dum eum peperisset pro augurio, ut } \\
\text { per ipsum omne augurium a Troia tolleretur, ancillis } \\
\text { precipit ut eum extra urbem in montibus proicerent. }\end{array}$ \\
\hline $\begin{array}{l}\text { Quem quidam pastor } \\
\text { adultum in dideo monte qui sub } \\
\text { troya est secum pastorem fecit. }\end{array}$ & $\begin{array}{l}\text { quod et factum est. et dum ab ancillis proiectus } \\
\text { fuisset, a quodam pastore qui in eodem monte } \\
\text { fuit collectus est et ab eo nutritus est. qui dum } \\
\text { adulesceret, coepit eum nutritor suus in vestibus } \\
\text { magnis, tamen in habitu pastorali ducere. }\end{array}$ \\
\hline
\end{tabular}

\footnotetext{
${ }^{26}$ Según Atwood y Whitaker (1944, p.59) no existen paralelos en la literatura clásica de la historia de la lucha entre los toros.
} 


\subsection{SEGUNDA GLOSA: INVULNERABILIDAD Y MUERTE DE AQUILES}

Esta glosa, adscrita también a la obra de Dares, se encuentra en el margen inferior del f.70r (Fig. 2). Ofrece un comentario moral relativamente extenso y la exposición del episodio mitológico resulta breve en comparación con la de la glosa anterior. La transcripción de su texto es la siguiente:

Achilles ut ait Homerus fuit Pelee regis et Tetis regine filius. [...] Narrat si quidem eum aqua inferorum fuisse induratum. et ideo gladio nullatenus adiri posse nisi per talum. Postea vero fraude deceptum Heccube Polixene cecatum spem. Alexandri gladio talo vita caruisse.

Como podemos observar, se hace alusión a dos acontecimientos claves en la vida de Aquiles, correspondientes al florecimiento y al ocaso de su existencia: por un lado, el momento en el que, aun siendo un niño, se vuelve prácticamente invencible gracias a la intervención de su madre y, por otro, el de su muerte.

El relato de la invulnerabilidad de Aquiles suele ir asociado al de su muerte, no porque lo uno sea consecuencia de lo otro, sino porque lo condiciona en gran medida. La referencia que hace la primera parte de la glosa al modo en el que el héroe se vuelve inmune podemos ponerlo en relación con el cap.10 del Excidium Troiae:

Et dicere habes: quare Achilles inter virgines inventus est? iste Achilles Pelei et Tetidis filius fuit, quem dum mater eius enixa fuisset, tenens talum eius duobus digitis capite deorsum in aqua inferorum que Stigie nuncupantur tinxit. et exinde stagnatus est, propterea ferrum eum nullo modo adire poterat, nisi tantummodo in talo ubi digiti matris eius quando eum tinxit tetigerant. et dum tractaret mater sua constellationem eius, responsum est ei: "Quia multos gladio perimet, etiam et ipse per ferrum morietur».

Aunque son muchas las fuentes que dan cabida a este episodio, lo habitual es que se ofrezca la información de manera parcial ${ }^{27}$. No obstante, tanto en el Excidium Troiae como en el texto glosado encontramos la versión completa y prácticamente el mismo esquema de exposición de los hechos, pues en ambos casos se comienza haciendo alusión al linaje de Aquiles ${ }^{28}$ y se continúa dando cuenta de casi todos los

${ }^{27}$ El dato más célebre sobre la muerte del héroe es el de que murió de un flechazo en el talón, siendo ésta la única parte vulnerable de su cuerpo porque al nacer lo había sumergido su madre en las aguas de la Estige, que lo hicieron invulnerable en todo su cuerpo menos en el talón por donde Tetis lo tenía cogido. No obstante, este dato aparece por primera vez atestiguado, con todos los detalles que hemos citado menos la mención explícita al talón, en STAT. Achill.1.268-270; la referencia al talón, como parte mortal de su cuerpo y en la que recibió el flechazo que le causó la muerte, pero sin ofrecerse ningún pormenor más, en HyG. Fab.107; que murió de un flechazo en el talón, sin más detalles, está en Apollod.Epit.5.3 y en Q. S.3.62; por último, que la única parte vulnerable de su cuerpo era aquella por donde su madre lo tenía cogido al sumergirlo en las aguas de la laguna Estige, lo afirman LACT.Achill.1.134 y 270, SERV. Aen.6.57 (el Myth. VAT. I reproduce casi las mismas palabras), SchOL. Hor. Epod.13.12, narrat. fabul. 12.6, y Fulg.Myth.3.7.

${ }^{28}$ La diferencia más evidente es que en la glosa mencionan a Tetis como 'reina', algo absolutamente normal en el contexto de un comentario moral cristiano. Además, el texto del Excidium Troiae que presenta este mismo 
detalles del proceso por el cual se hizo invulnerable: inmersión en el agua -aunque la glosa, pretendiendo sólo hacer referencia a los datos más relevantes, no menciona el nombre mítico que tradicionalmente reciben esas aguas-, posterior 'endurecimiento' $\mathrm{y}$, por tanto, inmunidad ante cualquier ataque y alusión al talón como único punto débil del aguerrido guerrero.

Por otra parte, al igual que en la glosa anteriormente analizada, también aquí hallamos evidentes paralelos formales que nos ayudan a sustentar nuestra hipótesis: el copista continúa con la tónica de introducir ligeras modificaciones -algunas de ellas como simplificación de palabras no muy comunes ${ }^{29}$ - pero aun así presenta manifiestas correspondencias con el Excidium Troiae no sólo en léxico sino también en sintaxis y orden de palabras:

\begin{tabular}{|c|c|}
\hline Glosa & Excidium Troiae \\
\hline$\underline{\text { Achilles }}$ ut ait homerus fuit & Iste Achilles Pelei et Tetidis filius fuit, quem dum mater \\
\hline Pelee regis et Tetis regine filius. & eius enixa fuisset, tenens talum eius duobus digitis capite \\
\hline$[\ldots]$ Narrat si quidem eum & deorsum in aqua inferorum que Stigie nuncupantur \\
\hline inferorum fuisse induratum. & tinxit. et exinde stagnatus est, propterea ferrum eum \\
\hline et ideo gladio nullaten & nullo modo adire poterat, nisi tantummodo in talo ubi \\
\hline posse nisi per talum. & digiti matris eius quando eum tinxit tetigerant. \\
\hline
\end{tabular}

Sin embargo, los relatos sobre la muerte de Aquiles ya no resultan coincidentes: en la glosa su muerte tiene lugar cuando Alejandro le clava su espada en el talón ${ }^{30}$, todo ello consecuencia de un engaño por parte de Hécuba (deceptum heccube) y del amor que el hijo de Tetis siente por Políxena (polixene cecatum spem); en Excidium Troiae 13 a Políxena, que ya está casada con Aquiles ${ }^{31}$, se le encomienda la misión ${ }^{32}$ de descubrir cuál es el punto débil de su marido para poder matarlo ${ }^{33}$; de esa manera conseguirían vengar la muerte de su hijo Héctor, por un lado, y obtener un cónyuge más digno para Políxena. Desvelado el secreto del héroe, los reyes de Troya urden una treta para acabar con él: le hacen creer que se va a realizar un sacrificio en el templo de Apolo, donde la costumbre era entrar desarmado y descalzo, y allí Alejandro le lanza una flecha envenenada al talón.

códice omite toda alusión a dioses o fábulas (esta información corresponde a la descripción que Bate [1986, p.13] ofrece del texto del Excidium Troiae del Matritensis 10046, pero es aplicable al ms. 126, cf. Del Castillo [2014]).

${ }^{29}$ Es el caso del trueque del verbo stagno -su acepción de 'consolidar' o 'endurecer' no es la más habitualpor el verbo induro, más sencillo y común en el latín del Medievo.

${ }^{30}$ Esto no es lo común en la tradición, pues usualmente el arma empleada suele ser una flecha.

31 Aquiles le ofrece a Príamo oro y, sobre todo, el cuerpo sin vida de su hijo Héctor a cambio de que le conceda la mano de Políxena en matrimonio. Finalmente, el rey accede a los requerimientos del héroe aun no estando de acuerdo con dicha unión (cap.13).

${ }^{32}$ Como no se tiene constancia de si este encargo fue realizado por Príamo o por Hécuba se les menciona a los dos como posibles conspiradores.

33 Existe un claro paralelismo con el episodio bíblico de Sansón y Dalila (Jue, 16.4-22). Cabe la posibilidad de que hubiera un influjo latente. 
Aunque la mano ejecutora es la misma en ambos casos, lo cierto es que los textos difieren en lo referente al arma empleada en el asesinato y, sobre todo, a las circunstancias que rodean el mismo. La relación de la muerte de Aquiles con su amor por la Priámide Políxena podemos encontrarla en numerosas fuentes ${ }^{34}$; no obstante, consideramos que en esta ocasión la glosa toma como base el texto de la De excidio Troiae historia (Dares 34) que, precisamente, se encuentra en el f.70v: Hécuba, que desea fervientemente vengar a sus hijos Héctor y Troilo, trama un plan para matar a Aquiles, contando con la ayuda de otro de sus vástagos, Alejandro; con el pretexto de contraer nupcias con Políxena, el héroe, aquí sí, cegado por su amor hacia ella, acude junto a Antíloco al templo de Apolo Timbreo, donde ambos son asesinados por Paris.

La posibilidad de que el copista pretendiera combinar de manera consciente estas dos fuentes en la glosa no nos resulta demasiado plausible; de manera que, a nuestro parecer, el amanuense debió de confundirse por desconocimiento de la leyenda genuina, por el mensaje ambiguo ${ }^{35}$ que reproduce el oráculo que sigue al relato sobre la invulnerabilidad del héroe - «Quia multos gladio perimet, etiam et ipse per ferrum morietur»)-y por la versión de su muerte que se refiere en la De excidio Troiae historia y que acababa de copiar ${ }^{36}$.

\section{DISPOSICIÓN Y CONTEXTUALIZACIÓN DEL EXCIDIUM TROIAE}

Como hemos comentado anteriormente, el Excidium Troiae del ms. 126 del Archivo Capitular de El Burgo de Osma ofrece únicamente dos tercios del texto, pues la primera parte al completo está omitida. Podríamos entender que, en este caso, el copista hubiera eliminado por voluntad propia toda esta porción de la obra con la intención de no redundar en aquellos contenidos ya desarrollados en la precedente ${ }^{37}$. No obstante, también hemos de tener en cuenta otros factores, entre ellos el hecho de que todos los manuscritos españoles que contienen la De excidio Troiae historia ${ }^{38}$ suelen colocar tras la obra ya finalizada una suerte de catálogo de héroes perecidos

\footnotetext{
${ }^{34}$ Cf. Hyg.Fab.110, Philostr.Her.20.16, Dict. 4.10 s., Serv.Aen.6.57 y 3.222, LaCt.Achill.1.134, DARES.34, Myth. VAT.1.36, 2.205, SCHOL. Lyc.269.

${ }^{35}$ La palabra ferrum puede referirse tanto a una espada como a la punta de una flecha.

${ }^{36}$ Las glosas de contenido, así como las anotaciones, aparecen escritas con la misma tinta y letra que el texto principal; además, prácticamente todas las que comentan y no completan presentan su propio pautado -realizado a lápiz de plomo, como el del cuerpo del texto-. Todos estos datos codicológicos, unidos a rasgos paleográficos concretos, nos llevan no sólo a postular la contemporaneidad de las glosas con respecto a la copia del códice, sino a considerar que la mano que reprodujo el texto principal hizo lo propio con las glosas. Cf. Del Castillo (2014).

${ }^{37}$ Ésta era la explicación que Bate (1986, p.13) otorgaba a la eliminación de la primera parte del Excidium Troiae que presenta el manuscrito 10046, empleado en su edición, puesto que no conocía la existencia del testimonio que alberga el ms. 126 de El Burgo de Osma. De cualquier manera, su apreciación se consideraba acertada en Cristóbal (2004, p.239).

38 Actualmente, las bibliotecas españolas albergan cinco testimonios de la obra de Dares: el ms. 8831 (s.XII) y el ya mencionado 10046 (s.XIV) de la Biblioteca Nacional; el R. II. 9 (s.XII) y el O. III. 16 (s.XV) de la Real Biblioteca del Monasterio de El Escorial y el ms. 126 (s.XIII) del Archivo Capitular de El Burgo de Osma, el que aquí nos ocupa.
} 
en combate durante la Guerra de Troya, tanto en el bando griego como en el troyano. Sin embargo en el ms. 126 -y, como consecuencia, en el ms. 10046- se traspone una breve porción de texto después del ya mencionado catálogo, el correspondiente a la salida de Eneas y Anténor de Troya como traidores, lo que conecta a la perfección con el comienzo del Excidium Troiae, cuyo incipit es: Incipit enee e troya exitus et eius ad ytaliam adventus (f.72vb.).

Desde la Antigüedad, pero fundamentalmente durante la Edad Media, se practicó en gran medida la compilación como técnica de organización del material, lo que dio lugar al origen de distintos géneros literarios tales como la enciclopedia, el compendio o el florilegio (Parkes 1976, pp.115-141). Asimismo, la disposición de las obras que componían un códice podía responder a la voluntad de crear un continuum narrativo que diera cierta homogeneidad. Éste parece ser el caso de seis manuscritos datados en el s. XIII, como el ms. 126, localizados en el área francesa, entre ellos el códice de Montpellier o tres manuscritos parisinos (BN. fr. 375, 794 y 1450) $)^{39}$, en los que trata de configurarse una historia legendaria para Inglaterra gracias a textos en romance como el Roman de Troie, el Roman d'Enéas, el Roman de Brut o las populares obras de Chrétien de Troyes.

Asimismo, nosotros también podríamos considerar que la estructura del manuscrito que nos ocupa responde a dos criterios fundamentales, lo que lo convertiría en un códice compilatorio: el género y la temática.

- A pesar de que en la actualidad nos resultaría difícil encuadrar las obras de este manuscrito dentro del género de la historia, lo cierto es que así eran consideradas en la Antigüedad. Y no sólo eso, todas tienen un factor común: los acontecimientos son narrados o están basados en los testimonios de testigos presenciales:

- La primera obra del códice es la Historia Hierosolymitana ${ }^{40}$, escrita en latín por Baudri de Bourgueil (cuyo nombre latinizado es Balderico) ${ }^{41}$, compuesta de cuatro libros que narran la historia de la Primera Cruzada (1095-1099). Se ha considerado que su veracidad es muy alta, puesto que se basó en la versión escrita por un testigo anónimo, probablemente un caballero normando, durante la propia Cruzada; la obra de este autor anónimo en la que se basó Baudri de Bourgueil para su Historia Hierosolymitana, la denominada Gesta francorum, tiene un gran valor como fuente de información, en particular en lo que respec-

\footnotetext{
${ }^{39}$ El códice de Montpellier presenta en sucesión el Roman de Troie, el Roman d'Enéas y el Roman de Brut, y se teoriza que la parte inicial que se ha perdido debería contener el Roman de Thébes (sobre dicha hipótesis cf. Constans [1890]). En el caso de los tres manuscritos mencionados, se inserta el Roman de Troie para crear una especie de prehistoria ideal para el mundo artúrico que encontrará su más alta consagración en el romance de Chrétien, $c f$. Punzi (1991, p.98).

${ }^{40}$ En Biddlecombe (2014), la edición más reciente de esta obra, tenemos una valiosa introducción en la que se habla sobre vida y obra del autor, la datación del texto, sus ideas principales, recepción y ediciones y manuscritos, entre los que se encuentra el ms. 126 del Archivo Capitular de El Burgo de Osma, en el que se basa casi por completo la edición de las dos epístolas que preceden al texto.

${ }^{41}$ Poeta e historiador francés, abad benedictino de Bourgueil y más tarde obispo de Dol-de-Bretagne. Vivió entre finales del s.XII y principios del XIII.
} 
ta al desarrollo del día a día de la expedición (itinerario, operaciones tácticas, logística) y a la mentalidad de los combatientes. Asimismo, tal como se refleja en la primera epístola que precede al texto, fue presentada para su corrección a Pedro, abad de Maizellais, que había acompañado a los cruzados -Epistola donum Baldrici Dolensis archiepiscopi ad Petrum Mallaecensem Abbatem-.

- La segunda obra del códice, la De excidio Troiae historia ${ }^{42}$ también está atribuida a un testigo presencial: Dares frigio. Como ya hemos comentado anteriormente, Dares dice ser militante en el bando troyano, lo que conlleva que su relato de la Guerra de Troya se presente al margen de leyendas y alusiones fantásticas a dioses o hechos sobrenaturales, impregnándola de un tratamiento más racionalista e histórico. Además, para conseguir dicho efecto, se emplea también el tópico del manuscrito encontrado, que tanta productividad ha tenido en la literatura: según consta en la epístola inicial, el texto pasa por ser la traducción de un original griego hallado en Atenas por Cornelio Nepote, el famoso historiador del siglo I a. C., quien, en esa misma epístola, le envía y presenta el relato «a su amigo Salustio Crispo», otro célebre historiador también del siglo I a. C. La utilización de nombres y personajes tan conocidos y relevantes intenta concederle autoridad a la obra y dotarla de prestigio, así como relacionarla directamente con autores representativos del género historiográfico.

- La última obra del códice es la Historia Karoli Magni ${ }^{43}$, datada en torno a la primera mitad del s. XII y escrita en latín por un tal Turpino del que no sabemos prácticamente nada. Según la Chanson de Roland (s. XI-XII) Turpino más que un eclesiástico era un intrépido guerrero que combatía valerosamente en las batallas y que habría muerto en Roncesvalles. No obstante, la Historia Karoli Magni comienza con una epístola ${ }^{44}$ (Epistola beati Turpini ad Leoprandum) en la que se aclara que este personaje en realidad no había perecido en combate, sino que mientras estaba recuperándose de sus heridas en Vienne había escrito el relato de las hazañas de Roland y Carlomagno.

- En relación con el segundo rasgo mencionado, además de que el códice esté compuesto por obras que reproducen hazañas de tipo bélico, consideramos que éstas comparten otro elemento: todas parecen desarrollar una temática relacionada, de una u otra manera, con Francia. Quizá dicha conexión quede patente en el caso de la primera y de la última obra ${ }^{45}$-la Historia Hierosolymitana y la Historia Karoli Magni-,

\footnotetext{
${ }^{42}$ A partir de ahora vamos a referirnos a las dos obras centrales, las de temática mitológica, como un todo homogéneo.

${ }^{43}$ La edición más reciente es la de Schmidt (1996).

44 Desgraciadamente, el códice muestra una pérdida de folios que afecta a la parte final del Excidium Troiae y al comienzo de la Historia Karoli Magni, por lo que la epístola está ausente.

45 Recordemos, asimismo, que la Historia Hierosolymitana va seguida del Exordium Cisterii-resumen del s.XII de algunos hechos que se describen en el Exordium Parvum - donde se habla de los inicios de la orden francesa de los cistercienses. La Summa Cartae Caritatis, que no está completa, es el reglamento o conjunto de estatutos de esta misma orden.
} 
pero es probable que precise de una mayor explicación en el caso del conjunto $D e$ excidio Troiae historia - Excidium Troiae.

- La leyenda fundacional de Francia se ve reflejada, de alguna manera, en dichas obras, puesto que se remonta al conflicto legendario más famoso de todos los tiempos: la Guerra de Troya. Al igual que el héroe fundador italiano, Eneas -cuyos viajes y posterior afincamiento en el Lacio se relatan en el Excidium Troiae-, Franción fue otro príncipe troyano, nieto de Príamo, que logró salvar su vida y escapar a la Europa central. Siglos más tarde, en el 396 d. C., el duque Marcomir efectuó la «mutacion des noms», de ahí en adelante la Galia se llamará Francia, en honor a Franción, y Lutecia tomará el nombre de París, en honor del troyano Paris, el raptor de Helena. Aunque este tema gozó de su máxima difusión en la literatura histórica del s. XV (Bossuat 1958, pp.187197), lo cierto es que la relación entre los orígenes de Francia y la Guerra de Troya empezó a aparecer mucho antes y cristalizó en la figura de Dares, que en torno a la mitad del s. XII sustituirá a determinadas fuentes como Virgilio, Ovidio o la Ilias latina. Se abandona la factura de poemas escritos generalmente en dísticos y que emulaban a estos antiguos poetas para escribir epopeya histórica en hexámetros; Dares se convierte en garantía de historicidad. No obstante, el ejemplo más palpable de esta relación data de unos siglos antes: la Historia Daretis Frigii de Origine Francorum ${ }^{46}$, datada en torno al s. VIII. Dicho texto está incluido en la crónica del Pseudo-Fredegario y se divide en dos partes: la primera es una reducción de la De excidio Troiae historia de Dares y la segunda reproduce la historia legendaria de los francos y los romanos después de la caída de Troya (Jung 1997, pp.190-191). Asimismo, en torno al s. XI este texto encuentra un lector atento en la figura de Fréchulf de Lisieux, que es el autor de la primera historia universal sobre el reino de los francos.

- Además de que el ms. 126 del Archivo Capitular de El Burgo de Osma cuente con Dares entre sus folios, las dos glosas anteriormente analizadas ofrecen referencias que conectan directamente la obra con nuestro país vecino. En la glosa en la que se desarrolla el episodio del nacimiento y juventud de Paris (f.62v) se arroja la siguiente información: Hic ut dicit Homerus binomius fuit. Dictus est enim Alexander et Paris a quo dicta est civitas parisius. Esta identificación etimológica entre el nombre de la ciudad de París y el héroe Paris resulta bastante curiosa puesto que, a pesar de que actualmente esta falsa etimología puede parecernos una obviedad, las referencias al origen legendario de París anteriores al s. XV son bastante raras; de hecho, la primera mención de esta etimología la encontramos en las Gesta de Rigord de Saint-Denis, escritas en los últimos años del s. XII ${ }^{47}$, poco tiempo antes de la copia de nuestro códice.

\footnotetext{
46 Su editio princeps fue llevada a cabo por Gaston Paris (1872).

${ }^{47}$ Para más detalles sobre esta falsa etimología $c f$. Bernard (2001), Bove (2004) y, sobre todo, Barroux (1955, pp.7-16) para conocer el panorama anterior al s.XV.
} 
Por otra parte, la segunda glosa analizada -invulnerabilidad y muerte de Aquiles (f.70r)- cuenta con una interesante referencia, pues, inserta en la parte de comentario moral, el artífice de la glosa habla de Aquiles en los siguientes términos: Alexander et enim noster hostis antiquus cotidie satagit et cogitat. Como podemos observar, el que escribe es franco o, al menos, de tradición romana, pues considera al héroe heleno como un antiguo enemigo, lo que enlazaría a la perfección con la idea de que los franceses se tenían por descendientes directos de los troyanos y, por tanto, primitivos rivales de los griegos. Además, como es bien sabido, los medievales no concebían hiato alguno entre ellos y la Antigüedad, esa idea no llegará hasta el Renacimiento.

Aunque la influencia francesa en la Baja Edad Media española es tan conocida y admitida que no necesita justificaciones, nos gustaría dar unas pinceladas sobre la misma en la zona de El Burgo de Osma. A pesar de que la trayectoria de este códice resulta bastante incierta, podríamos poner en relación dicho contenido con la historia de la Reconquista, a comienzos del s. XII. Después de que Alfonso VI de León y Castilla (1047-1109) asumiera el control total del territorio heredado de su padre, hizo venir de Francia a Bernardo Salvitá, monje cluniacense que llegó acompañado de otros jóvenes sacerdotes, y lo nombró arzobispo de Toledo. Como consecuencia, un buen número de órdenes religiosas españolas quedaron bajo el control de la orden francesa de los cluniacenses. Asimismo, con la llegada de Bernardo Salvitá, se restableció de manera definitiva el obispado de Osma, cuyos tres primeros obispos -San Pedro de Osma (Pierre Bourges), Raimundo de Toledo (Raimundo de Sauvetat) y Beltrán de Osma- fueron franceses. Dado que no existe ningún indicio en el códice que testimonie su paso por otras bibliotecas, consideramos que fue importado de Francia o copiado en España, concretamente en Osma, por monjes franceses o de influencia francesa ${ }^{48}$ y que se ha conservado en la biblioteca de la Catedral desde ese momento ${ }^{49}$.

\section{CONCLUSIONES}

Como hemos podido observar a lo largo de estas páginas, parece que el ms. 126 del Archivo Capitular de El Burgo de Osma presenta unos contenidos estructurados de forma unitaria y coherente. Por tanto, este hecho tiene una serie de implicacio-

\footnotetext{
${ }^{48}$ En Tischler (2002, p.130) se apunta la posibilidad de que el códice fuera importado de Francia por Diego de Acebes, obispo de Burgo de Osma desde 1201 hasta 1207, y por Domingo de Guzmán, a quien nombró su canónigo, puesto que al regreso de ambos de Roma durante la primavera de 1206 se detuvieron en algunos monasterios franceses, entre ellos el monasterio principal de la orden del Císter. No obstante, aunque nos resulta plausible, nosotros preferimos abarcar también otras posibilidades, teniendo en cuenta la relevante presencia e influencia francesa en El Burgo de Osma.

${ }^{49}$ Existe un inventario datado a finales del s.XIII conservado en un códice que la biblioteca capitular ya albergaba por entonces; en él se hace mención de un ejemplar manuscrito que contenía una«ystoria troiana», que podría tratarse del actual ms. 126. Para acceder a la totalidad de los datos recogidos en dicho inventario $c f$. Rojo Orcajo (1929, pp.9-13).
} 
nes a la hora de disponer los mismos: a pesar de que el número de obras es mayor, podríamos hablar de la existencia de tres bloques, pues, por una parte, el Exordium Cisterii y la Summa Cartae Caritatis funcionan como un apéndice de la Historia Hierosolymitana ${ }^{50}$, y por otra, el Excidium Troiae como una continuación natural de la De excidio Troiae historia (de hecho su disposición en el códice [Del Castillo 2014, p.66]. y la falta de su primera y última parte pueden haber propiciado el hecho de que este testimonio manuscrito haya permanecido en la sombra durante tanto tiempo). El copista o, en este caso, el compilador parece establecer un unicum homogéneo a través de dos obras de distinta naturaleza pero, al mismo tiempo, complementarias, de modo que utiliza el Excidium Troiae como una herramienta que moldea de acuerdo con dichos intereses: elimina la primera parte para no redundar en contenidos, pero de esta misma emplea porciones para la elaboración de glosas.

Asimismo, debemos recordar que el Excidium Troiae, aunque gozó de una notable difusión durante el Medievo, carece de autoría y, por tanto, de auctoritas ${ }^{51}$, elemento indispensable para garantizar el prestigio y la supervivencia de cualquier texto. Copiarlo solo, sin adscribirlo a ningún autor de renombre resulta poco práctico, de modo que en el caso que nos ocupa, lo han atribuido a Dares, por un lado, y al 'Homero' mencionado en las glosas, por otro.

De manera que podríamos concluir que el escriba no sólo contaba con el texto de Dares sino también con un ejemplar completo del anónimo Excidium Troiae ${ }^{52}$ y que mediante las dos obras habría confeccionado una suerte de relato único sobre la Guerra de Troya y, por ende, sobre los orígenes legendarios de Francia, eliminando aquellas partes que consideraba superfluas o reiterativas y glosando aquellas otras que consideraba de interés. Estaríamos, por tanto, ante otro ejemplo de códice compilatorio.

\section{REFERENCIAS BIBLIOGRÁFICAS}

Atwood, E.B. - WhitaKer, V.K. (1944), Excidium Troiae, Cambridge [Mass.]

ATwood, E.B. (1937), «The Excidium Troiae and medieval Troy literature», Modern Philology 35.2, 115-128.

BARroux, M. (1955), «Les origines légendaires de Paris», Paris et Île-de-France. Mémoires 7, 7-40.

Bate, A.K. (ed.) (1986), Excidium Troiae, Frankfurt / Bern / N. York, Peter Lang.

BenNetT, A. (2005), The Author, New York, Routledge.

\footnotetext{
${ }^{50}$ El Exordium Cisterii aparece, como ya hemos comentado, a continuación de la Historia Hierosolymitana pero en otro folio. No obstante, no presenta diferenciación codicológica que permita considerarla como obra independiente; asimismo, su incipit la pone en relación directa con la obra precedente: Uno anno ante ereptionem iherusalem de manu turcorum impiorum ordinem cisterciensem incoasse hoc modo (este incipit está escrito a tinta negra, en minúsculas y precedido por un nota bene escrito de forma anagramática).

${ }^{51}$ Sobre el concepto de auctoritas y auctor cf. Minnis (2010) y Bennett (2005).

${ }^{52}$ Se trataría de un hecho notable, puesto que la triple división del relato ha hecho que varios de sus códices contengan sólo una o dos partes de este total. Cf. Cristóbal (2004, p.239).
} 
Bernard, J.P. (2001), Les deux Paris: les représentations de Paris dans la seconde moitié du XIXe siècle, Champ-Vallon, 01420 Seyssel.

Biddlecombe, S. (2014), The Historia Ierosolimitana of Baldric of Bourgueil: a new edition in Latin and an analysis, Woodbridge, Suffolk, U.K., Boydell Press.

Bossuat, A. (1958), «Les origines troyennes: leur rôle dans la littérature historique au XVe siècle», Annales de Normandie 2, 187-197.

Bove, B. (2004), «Aux origines du complexe de supériorité des Parisiens: les louanges de Paris au Moyen Âge», Paris et Île-de-France. Mémoires. Être parisien 55, 423-444.

Constans, L. (1890), Le Roman de Thébes, édition critique d'après tous les manuscrits connus, 2 volls., París, Les Belles Lettres.

Cristóbal, V. - Del Barrio, F. (2001), Ilíada Latina. Dictis y Dares, Madrid. Gredos.

Cristóbal, V. (2004), «Dido y la Eneida en el Excidium Troiae» en Amado RodríGuEz, T. et alii (eds.), Iucundi acti labores: Estudios en homenaje a Dulce Estefanía Álvarez, Santiago de Compostela, Universidade de Santiago de Compostela, pp.239-245.

Dederich, A. (1835), De excidio Troiae historia, Bonn, Weber.

Del Castillo, N. (2014), «El ms. 126 del Archivo Capitular de Burgo de Osma: un nuevo testimonio del Excidium Troiae», $C F C(L)$ 34.1, 61-72.

FAIVRE D'ArcIER, L. (2006), Histoire et géographie d'un mythe: La circulation des manuscrits $d u$ De excidio Troiae de Darès le Phrigien (VIII $-X V^{e}$ siècles), París, Ecole des chartes.

GrubBS, H.A. (1933), The manuscript book collections of Spain and Portugal, Nueva York, A Union World Catalog of Manuscript Books.

Jung, M.R. (1997), «L'histoire grecque: Darès et les suites», en BAUMGARTNER, E. - HARFLANCNer, L., (EDS.), Entre fiction et histoire. Troie et Rome au Moyen Âge, París, Presses Sorbonne Nouvelle, pp.185-206.

MeIster, F. (1983), Daretis Phrygii De excidio Troiae historia, Leipzig, Teubner.

Minnis, A. (2010), Medieval Theory of Authorship: Scholastic Literary Attitudes in the Later Middle Ages, $2^{\mathrm{a}}$ ed., Philadelphia, U. of Pennsylvania Press.

Octavio De Toledo, J.M. (1903), «Catálogo de la Librería del Cabildo Toledano», Revista de Archivos, Bibliotecas y Museos 1, s.v.

PARIS, G. (1872), «Historia Daretis Frigii de origine francorum», Romania 3, 129-144.

PARKES, M.B. (1976), «The Influence of the Concepts of Ordinatio and Compilatio on the Development of the Book», en AleXAnder, J.J.G - GiBson, M.T. (eds.), Medieval Learning and Literature: Essays Presented to Richard William Hunt, Oxford, Clarendon, pp.115-141.

Pavano, A. (1993), «Contributo allo studio della tradizione manoscritta della De excidio Troiae di Darete Frigio», Sileno 19, 525-532.

Pellegrin, E. (1953), «Manuscrits des auteurs classiques latins de Madrid et du Chapitre de Tolède», Bulletin d'Information de l'Institut de Recherches et d'Histoire des Textes 2, 7-24.

PunzI, A. (1991), «La circolazione della materia troiana nell'Europa del '200: Da Darete Frigio al Roman de Troie en prose», Messana 6, 69-108.

Rojo Orcajo, T. (1929), Catálogo descriptivo de los códices que se conservan en la Santa Iglesia Catedral de Burgo de Osma, Madrid, Tipografía de Archivos.

Rubio FERnández, L. (1984), Catálogo de los manuscritos clásicos latinos existentes en España, Madrid, Ed. Universidad Complutense.

Ruiz De Elvira, A. (2011), Mitología Clásica, Madrid, Gredos. 
Schmidt, P. G. (1996), Historia Karoli Magni et Rotholandi, Stuttgart - Leipzig, B.G. Teubner. Stolmmann, J. (1968), De excidio Troiae historia, Wuppertal, Untersuchungen und kritische Ausgabe.

Tischler, M. (2002), «Ad vestigia S. Dominici... Eine neue Handschrift des “Exodium Cisterii” und der "Summa Cartae Caritatis”, Kap.1-3 in Burgo de Osma», Faventia 24.2, 127-142.

\section{ANEXO}
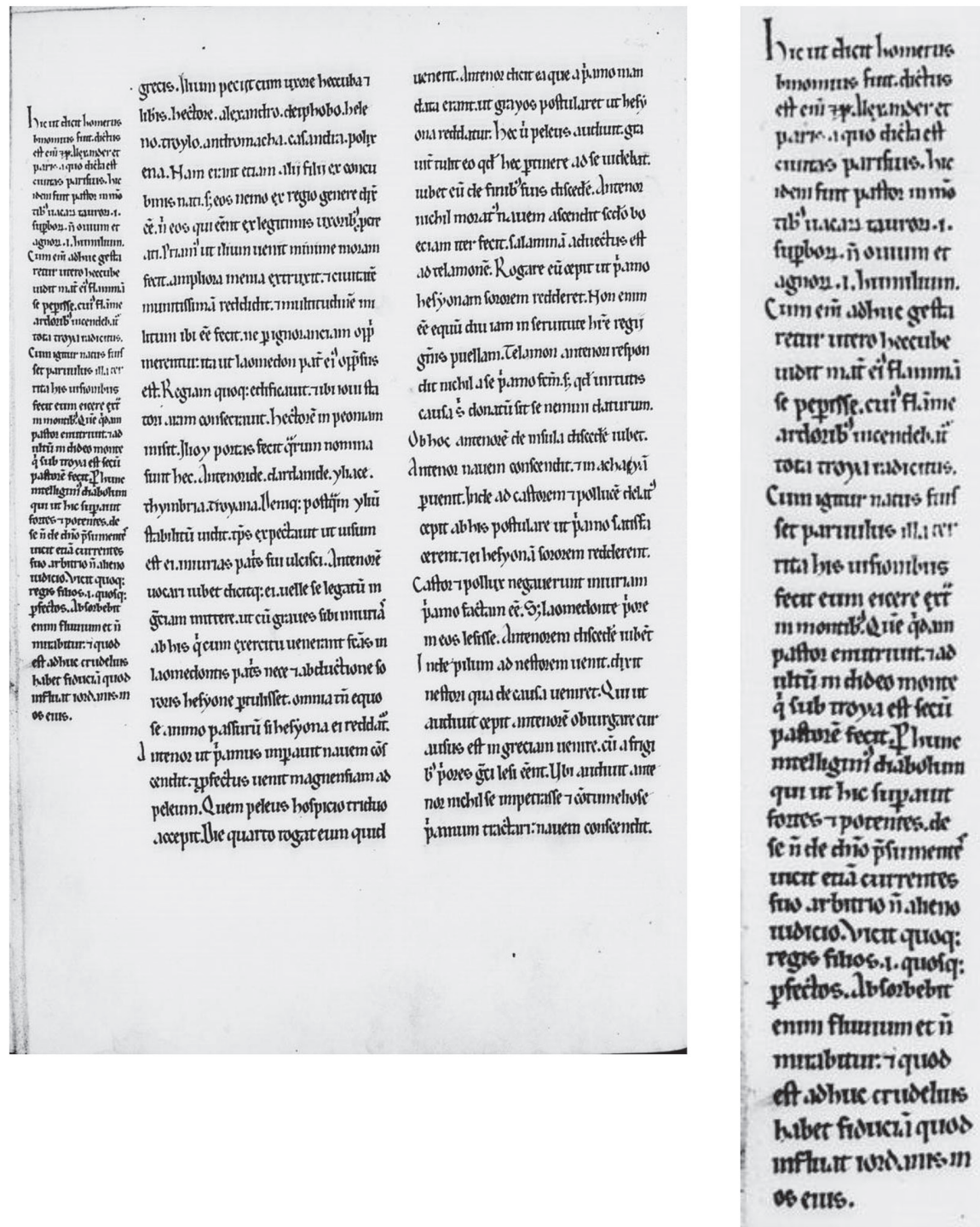

Figura 1: f.62v y detalle de la glosa 


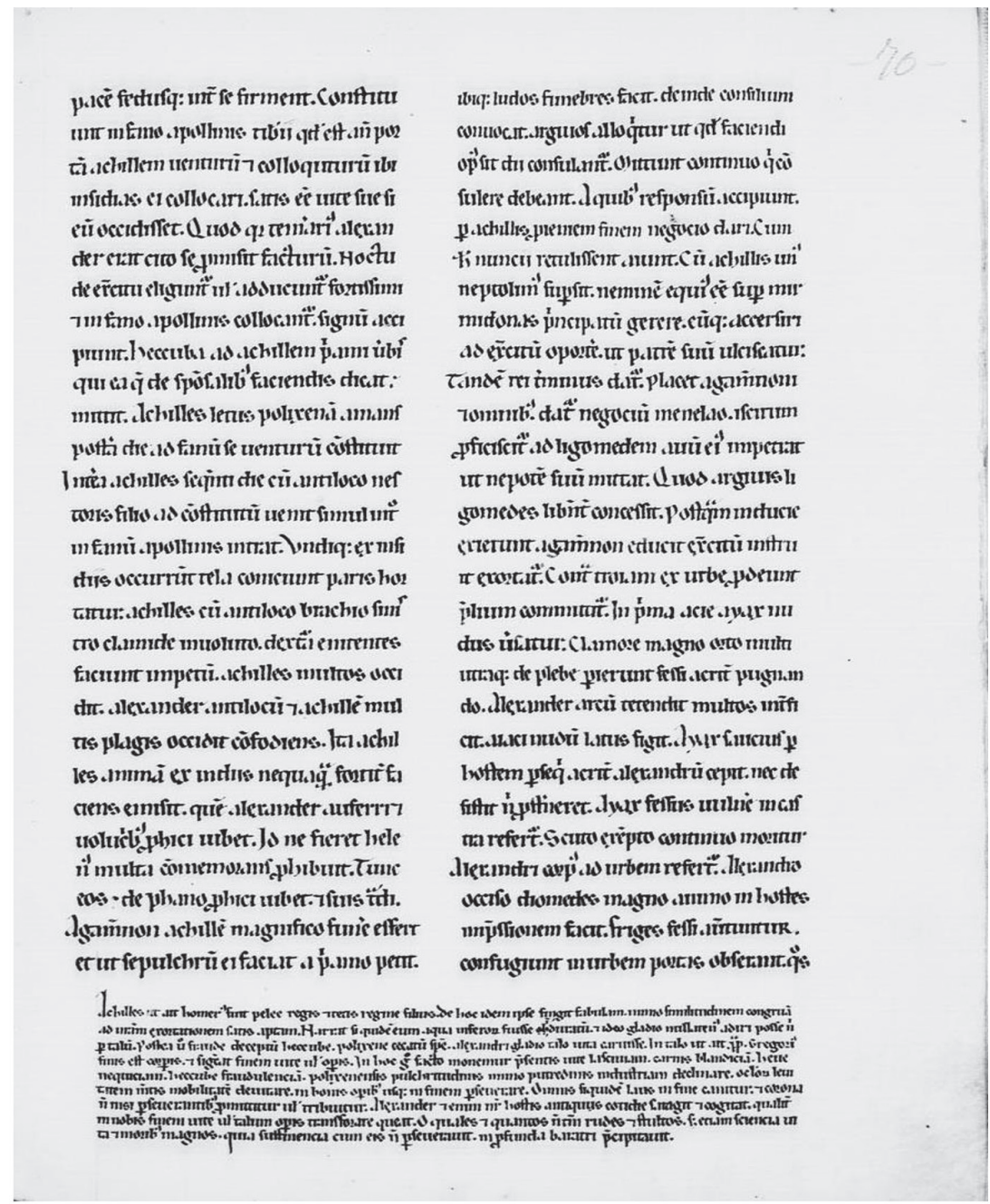

1

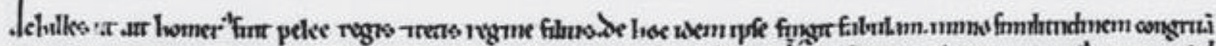

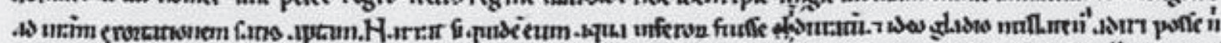

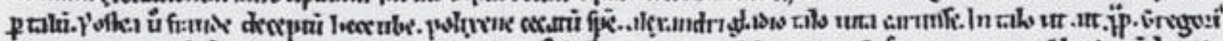

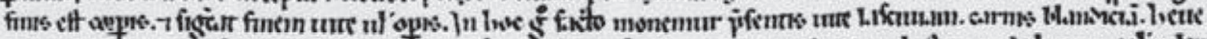

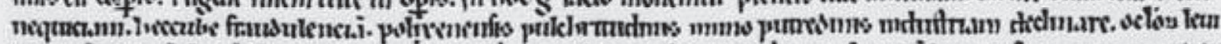

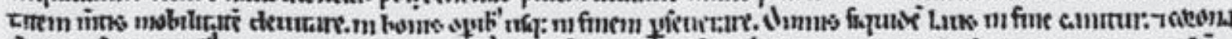

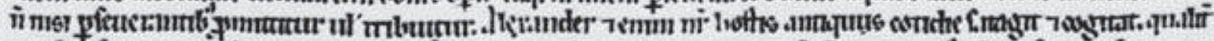

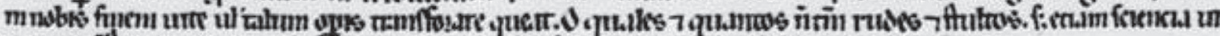

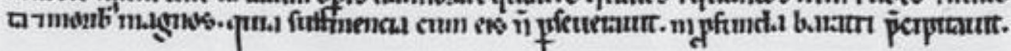

Figura 2: f.70r y detalle de la glosa 